\title{
Mind-life continuity: A qualitative study of conscious experience
}

\author{
Inês Hipólito ${ }^{\mathrm{a},}$, Jorge Martins ${ }^{\mathrm{b}}$ \\ a Faculty of Law, Humanities, and the Arts, University of Wollongong, Australia \\ ${ }^{\mathrm{b}}$ Faculty of Medicine, University of Lisbon, Portugal
}

\section{A R T I C L E I N F O}

\section{Article history:}

Received 30 May 2017

Received in revised form

1 September 2017

Accepted 2 September 2017

Available online 5 September 2017

\section{Keywords:}

Conscious experience

Qualitative study

Meditation

Autopoiesis

Mind-life continuity thesis

\begin{abstract}
A B S T R A C T
There are two fundamental models to understanding the phenomenon of natural life. One is the computational model, which is based on the symbolic thinking paradigm. The other is the biological organism model. The common difficulty attributed to these paradigms is that their reductive tools allow the phenomenological aspects of experience to remain hidden behind yes/no responses (behavioral tests), or brain 'pictures' (neuroimaging). Hence, one of the problems regards how to overcome methodological difficulties towards a non-reductive investigation of conscious experience. It is our aim in this paper to show how cooperation between Eastern and Western traditions may shed light for a nonreductive study of mind and life. This study focuses on the first-person experience associated with cognitive and mental events. We studied phenomenal data as a crucial fact for the domain of living beings, which, we expect, can provide the ground for a subsequent third-person study. The intervention with Jhana meditation, and its qualitative assessment, provided us with experiential profiles based upon subjects' evaluations of their own conscious experiences. The overall results should move towards an integrated or global perspective on mind where neither experience nor external mechanisms have the final word.
\end{abstract}

๑ 2017 Published by Elsevier Ltd.

\section{Contents}

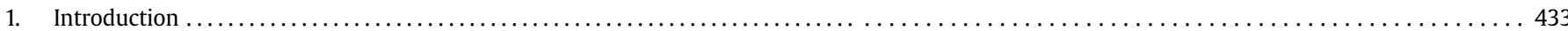

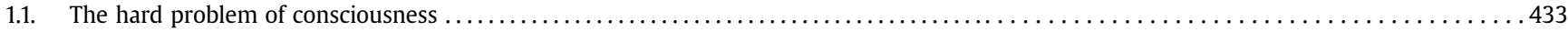

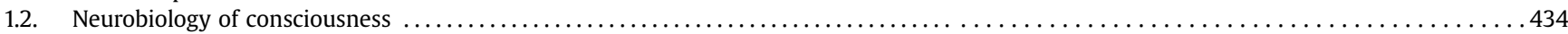

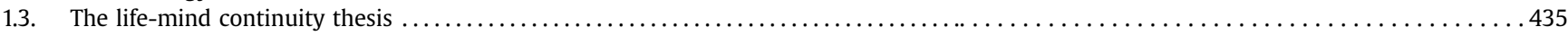

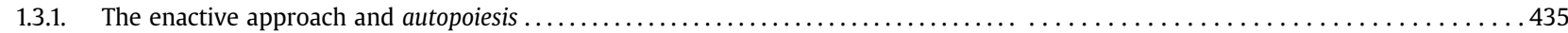

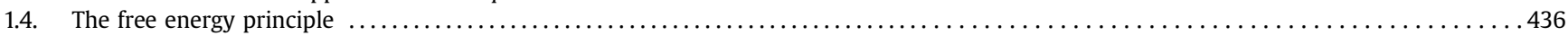

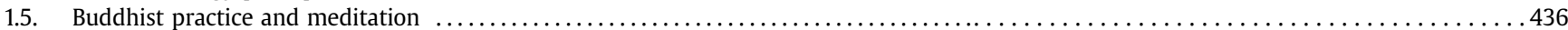

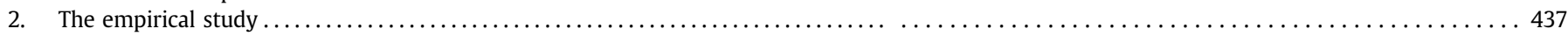

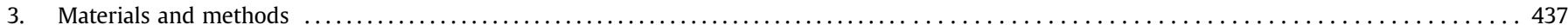

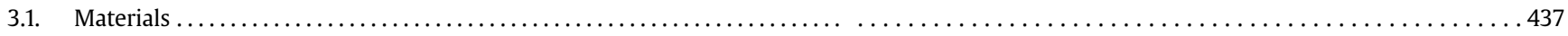

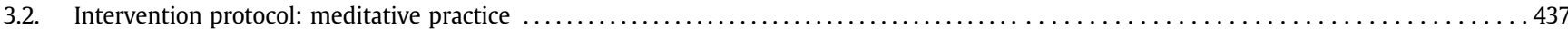

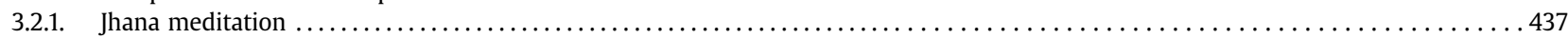

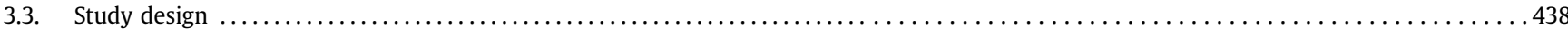

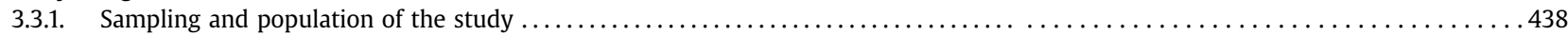

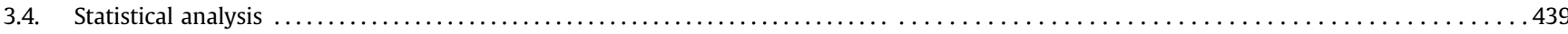

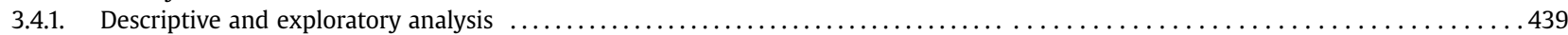

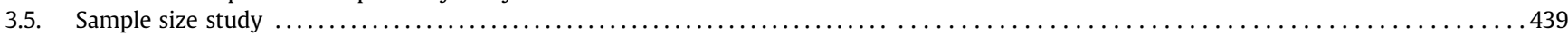

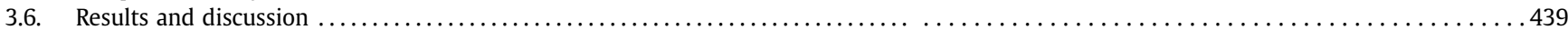

\footnotetext{
* Corresponding author.

E-mail addresses: inesh@uow.edu.au (I. Hipólito), jorge.e.martins@campus.ul.pt (J. Martins).
} 


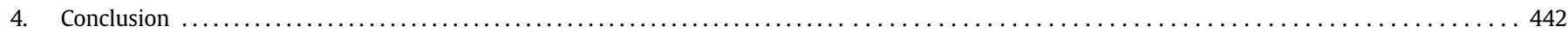

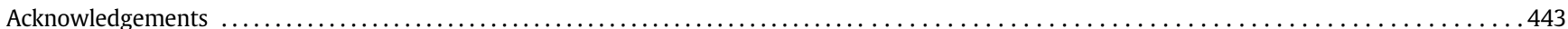

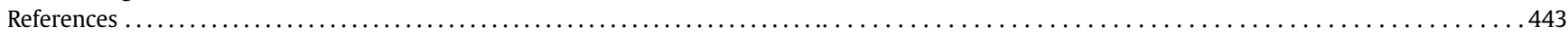

the individual feels the vanity of human desires and aims, and the nobility and marvellous order which are revealed in nature and in the world of thought.

Albert Einstein on Buddhism (1930)

\section{Introduction}

Thousands of years ago, long before the dawn of science, perceptive access to the world enabled human beings to conduct their affairs. As Koffka (1935, p. 7) put it: "To primitive man each thing says what it is and what he ought to do with it: a fruit says, "Eat me"; water says "Drink me"; thunder says "Fear me"”. Over time, by encountering both veridical and erroneous cases in their original world, human beings learned to distrust what things told them, and henceforth developed a new system founded no longer on particulars, but on universals. While the world of primitive man directed his experience-telling him what was good, bad, dangerous, healthy, or safe-today the world of scientific man guides human experience through the intellect, logic, and verified data.

Throughout the ages, however, a challenging question in science has remained, viz. why does physical sensory stimulation have to be accompanied by subjective experience? Were this not the case a neurobiological explanation would suffice, and Beethoven composing the Ninth Symphony, or Gödel working on his theorems ${ }^{1}$ could be explained by the stimulus-response schema. Subjective phenomena, ${ }^{2}$ which constitute the very texture of our existence, are difficult to describe and have thus far been excluded from scientific investigation. This is a very difficult topic for experimental research, particularly because modern Western science starts by quantification, and assumes that psychological experience can be expressed in purely quantitative terms (Weber's law). Of course scientists recognize that only because somethings escape quantification, it does not mean they are to be dismissed from science. On the contrary, as His Holiness the Dalai Lama remarks,

"It seems that scientific research reaches deeper and deeper. But it also means that more and more people, at least scientists, are beginning to realize that the spiritual factor is important. I say 'spiritual' without meaning any particular religion or faith, just simple warmhearted compassion, human affection, and gentleness. It is as if such warmhearted people are a bit more humble, a little bit more content... If we do not combine science with these basic human values, then scientific knowledge may sometimes create trouble, even disaster" (His Holiness the Dalai Lama, cited in Varela, 1997, pp 4-5).

How, then, do we explain subjective phenomena in a nonreductive metaphysics of the human mind? Psychology, neuroscience, philosophy, and physics, among other areas, study the nature

\footnotetext{
${ }^{1}$ For a phenomenological account of Mathematics, see Hipólito (2015).

2 Conscious experiences such as: when an idea comes to mind; when a childhood memory suddenly returns; when we enjoy a piece of music, or taste a good wine; when we read a novel, or write a letter; or when we watch the sunset, or visit an art gallery, and so on.
}

of the subjective phenomenon. Their progressive specialization has marked scientific progress both in Eastern and Western views, experimental and theoretical. This specialization and separation was necessary, but it has inevitably worked against the aim of an integral science (Simeonov, 2010), i.e., a science that is plurally constituted. Owing to this, we propose to look at a new perspective within the study of the mind and subjective experience. This perspective is based on the principle of interdependence between the constituting disciplines, in a dialogue between Eastern and Western traditions. In this paper, it is our aim to show empirically how theoretical cooperation between these traditions may shed light on a non-reductive understanding of life and mind.

A unified approach can be rigorously formulated to accommodate qualitative analysis and quantitative measurements. In our study, we combined a psychological assessment with a molecular measurement of protein profiles, with the aim of contributing to the phenomenological investigation of subjective experience. This is the first in a series of papers in which we focus on the intervention methodology adopted, viz. Buddhist meditative practice. We begin the paper by introducing the hard problem of consciousness, discussing the various answers it offers with regard to the phenomenological investigation of subjective experience. We focus in particular on the Western neurobiology of consciousness hypothesis, and the life-mind continuity thesis. We expect the results of our qualitative experiment (section 4) to show alignment with the life-mind continuity thesis.

\subsection{The hard problem of consciousness}

It is uncontroversial that consciousness is present when, for example, a student attends a class, in a spectator's excitement at a football game, when Galileo worked on his physics, or when Shakespeare wrote Hamlet. These activities can be described molecularly as processes whereby excitation on the sensory surface of an animal is conducted by nerve fibres to nerve centers, switched over to efferent nerves, and resulting in muscle contraction or gland secretion. Ordinary man, however, knows nothing of the molecular processes of conscious experience, but he certainly knows what it is like to experience a football game or a sunset by the sea.

The East and West provide distinctive conceptions of this subjective experience. Western medicine, for instance, tends to see the mind and body as "split," comprising two separate entities. Eastern traditions, by contrast, suggest that mind and body derive from the same energy (source). These conceptions of consciousness pose more than philosophical issues, particularly because, in the West, dualism between the mind and body has affected how patients are perceived and treated.

The problem of consciousness has occupied the best human minds for thousands of years, and has generated two most common ways of facing the hard problem of consciousness in western science, the physicalist and the dualistic view.

1. The whole problem is illusory. This response holds that there are not two kinds of substance or modes of existence, matter, and mind, but only one, viz. matter. Matter is composed of blindly whirling atoms that, owing to their great numbers and time 
available, form all sorts of combinations, among them those we call animals and human beings. Thus, it is scientific conviction that thinking and feeling are merely movements of atoms, even including the feeling of awe accompanying the moment of remarkable scientific discoveries. This materialistic conception of mind has served science well, building up physical and physiological knowledge. Nevertheless, difficulty resides in the fact that between life and mind this conception of consciousness makes an arbitrary discrimination with regard to scientific dignity. They have accepted matter and rejected mind, while each of them may in fact disclose as much of the truth as the other.

2. The second solution draws a Cartesian line between life and inanimate nature belonging together. This response places mind and life together as directed by a power not found in inorganic nature, and therefore as essentially different from it. However, this response does not solve but rather re-emphasizes the problem. Numerous speculative attempts have been made to overcome dualism. But pretending that a new name provides a solution to it may do a great deal of harm to science were it to be widely accepted.

Cartesian dualism is theoretically rejected in contemporary science, although, as previously mentioned, in practice we see too often a gap between the body and the mind in western science. The procedure is either to look for the subjective phenomena in the brain (bottom-up paradigm), or to theoretically reject the subjective phenomena while investigating brain function (top-down paradigm). Science cannot empirically deny subjectivity as an ontological phenomenon, nor can it verify or falsify subjective phenomena.

Subjective phenomena have been identified as the hard problem of consciousness (Chalmers, 1995). The hard problem concerns why physical stimulation must be presented to consciousness with a subjective feel. As David Chalmers frames problem (1995, p. 3).

It is widely agreed that experience arises from a physical basis, but we have no good explanation of why and how it so arises. Why should physical processing give rise to a rich inner life at all? It seems objectively unreasonable that it should, and yet it does.

The subjective aspect of experience, elicited from sensory stimulation, was illustrated by Frank Jackson (1982) in a thought experiment known as "the knowledge argument" against physicalism. It can be summarized as follows. Mary is a neurophysiologist who happens to be color blind from birth, but nevertheless specializes in perception and color. Imagine that she knows all there is to know in physical terms about perception before she in fact perceives red for the first time. Would she know what it is like to perceive red? Notwithstanding all the knowledge Mary has about the neurophysiology of sight-however detailed it may be-this knowledge cannot give her the experience of what it feels like to see a red rose. Jackson's thought experiment attempts to establish, first, that there are non-physical properties, and second that knowledge of these properties can only be attained through conscious experience. Thus, Jackson's thought experiment attempts to refute the claim that all knowledge is physical knowledge. To the contrary, conscious experience must involve non-physical properties because someone with complete physical knowledge about some phenomenon might yet lack knowledge about how it feels to experience the phenomenon itself. From this it follows that Mary does not know what if feels like (Nagel, 1974) to see red until she in fact sees red, sc. until she has had the conscious, phenomenal experience of red.

Easy problems, on the other hand, are those that fall within the scope of neuronal and cognitive function. These are usually studied through statistical and computation measurements. Such measuring techniques include behavioral models of yes/no responses (button-pushes, time-responses, etc.), and neuroimaging. Cognitive functions, such as memory, attention, sensory stimulation, are empirically investigated and explained by the standard methods and tools of cognitive science, viz. by computational or neural mechanisms (Chalmers, 1995, p. 2). On these models, to explain access (to consciousness) and reportability (language), for instance, we need only specify the mechanisms by which information about internal states is retrieved and made available for verbal report. To explain the integration of information, we need only exhibit mechanisms by which information is brought together and exploited by later processes. For an account of sleep and wakefulness, for example, an appropriate neurophysiological account of the process responsible for an organism's contrasting behavior in those states will suffice. As Chalmers (1995, pp. 2-3) explains:

In each case, an approximate cognitive or neurophysiological model can clearly do the explanatory work [...] If this phenomena were all there was to consciousness, then consciousness would not be much of a problem.

In cognitive science the hard problem of consciousness, or of subjective phenomena, comes up again and again. Indeed, it is wellknown to those who study brain function, such as LeDoux, Antonio Damásio, Gerhard Roth, and Francisco Varela. There are two fundamental models to understanding the phenomenon of mind. The first is the computational model, based on symbolic thinking paradigm; the second is the biological organism model, based on the natural life paradigm. The latter involves the thought that we should understand mind from the perspective of life and evolution. In what follows, we will briefly present and discuss two versions proposed within the biological model.

\subsection{Neurobiology of consciousness}

In recent years, neuroscientists have intensively studied the cerebral activity correlated with conscious experience. Patterns of cell activity have been detected from PET and fMRI scans, which are commonly seen as showing the mind in action. It is said that we can now see where mental arithmetic occurs, where words are formed, where lies are generated, and even where our religious sentiments are located (albeit what we are in fact witnessing are changes in oxygen levels in the blood during these mental activities).

The embryonic neurobiology of consciousness was introduced by Crick and Clark in their The Astonishing Hypothesis (1994), followed by The Quest for Consciousness by Koch (2004), which further lays down paths to be explored in the next several decades. Koch is optimistic that careful scientific research will provide the answers, but is less impressed with the theoretical limits imposed by philosophers. Although Koch admits that philosophers have frequently formulated questions that challenge scientists, philosophical constraints are often overlooked (Martinez-Conde, 2004). Their model proposes a neurobiological account of experience. Koch narrows down the neural correlates of consciousness for visual consciousness to coalitions of neurons in and around the inferior temporal cortex, projecting to the frontal lobes and supported by feedback activity from the cingulate and frontal cortices. The function of consciousness, he states, is to provide an "executive summary" of the world's status to the planning stages of the brain (i.e. the frontal lobes). Thus, consciousness may be an intermediate-level process (see Jackendoff's, 1987) limited to intermediate brain areas. This view has been illustrated with the idea of a homunculus, sc. the explanation of (human) vision by assuming there is an internal 'viewer', namely a 'little man' or 'homunculus' inside the brain 
'looking at a movie' inside a theatre (this has also been called the Cartesian Theatre). The homunculus argument has, however, been the target of criticism and is today generally seen as a fallacy. Another source of difficulty regards how to metaphysically define, and ontologically conceptualize, "visual consciousness". In empirical investigation, one should be cautious when establishing metaphysical correlations of levels of reality. It seems the object of Koch's study is 'vision awareness', that is, the relation between attentional function and vision stimulation, which would fall naturally within the purview of the easy problems. It has, however, nothing to do with how subjects experience a certain phenomenon. In other words, it fails to explain the phenomenological experience accompanying sensory stimulation.

Antonio Damásio proposes a theory about the neural basis of consciousness that contests the idea of a homunculus inside the brain (Damásio, 1994, 2010). On Damásio's view, consciousness is a private, first-personal phenomenon that can be studied by combining cognitive and neurobiological methods in order to describe its cognitive nature, behavioral correlates, possible evolutionary origin, functional role, and finally its neuroanatomical and neurophysiological underpinnings (Damásio, 1998). Phenomenal conscious content is, in Damásio's view, a matter of associations that are processed in different brain areas at the same time. More specifically, what makes a conscious state feel like something rather than nothing is explained as a fusion of mind and body, in which neurons become "extensions of the flesh." Phenomenal consciousness is enabled as the result of a procession of neural maps of inner and outer worlds. Indeed, this is what Damásio names self-consciousness. Without a self, the mind would lose its orientation: thoughts would be freewheeling, unclaimed by an owner, and we would almost certainly look unconscious (Damásio, 2010; chap. III).

Damásio makes a distinction between three levels of "self", which build upon each other to construct the kind of full-blown consciousness that humans are privileged to experience. On his view, the most basic form of self-the "protoself"-is a neural map of an organism's internal status, i.e., related to primordial feelings of the body present in the normal, waking brain (p. 191). The "core self" is what further extends the "protoself", namely by incorporating interactions between an organism and its environment. It provides personhood, and firmer senses of being. At the highest level, there is the "autobiographical self", which adds information about an organism's past and its expectations about the future. With language as a useful medium, memory and reasoning are enhanced. With this enhancement, narratives become possible, giving the "core self" the sense of being a protagonist, that is, an "autobiographical self".

Damásio's theory is largely centered on the notion and levels of self as exemplified by the brain. His theory relies on neuroimaging techniques and determines that experience results from internal or external physical stimuli. This view therefore requires understanding experience on its reductive construal. Damásio (1994, 2010) rejects dualism by bringing consciousness back to the body (sc. brain function). The reduction of experience to brain function returns us squarely to a reductionist view of consciousness.

Damásio's theory is in opposition to other biological approaches, such as the life-mind continuity thesis. According to the latter, notions of both conscious phenomena and selflessness play an essential role.

\subsection{The life-mind continuity thesis}

A variety of phenomena in human experience reveal that, within different evolutionary levels of living organisms, life and mind cannot be thought of as two distinct phenomena. To the contrary, mind and life are two indispensable categories that, by virtue of their internal relation and identical ontology, form a whole.

According to the mind-life continuity thesis there are three levels (Godfrey-Smith, 1998). On the weak continuity view, whatever has mind will have life, although not all things that have life have mind. Cognition is a kind of activity of a living system. On the strong continuity view, life and mind have a common abstract model or set of basic organizational properties. The functional properties of mind are usually the indispensable properties of life. On the methodology continuity view, the understanding of mind requires further understanding the role that it plays in the whole living system (pp. 72-73). Each of the views within the life-mind continuity thesis share the perspective that cognition should be studied in the context of "the whole organism" (Godfrey-Smith, 1998).

\subsubsection{The enactive approach and autopoiesis}

The life-mind continuity thesis is accommodated by enactive cognitive science. This is the biological model that emerges from the theory of autopoiesis. Autopoiesis aims to correlate the data from brain, mind, and consciousness studies (particularly neuroscience laboratory work), with phenomenological insights in the understanding and explanation of subjective experience, and ongoing reflection on one's own personal consciousness, as conceived by Buddhism (Varela et al., 1993; Varela, 1996, 1999; Hayward and Varela, 1992).

Autopoiesis is a theory concerning the inextricable link between life and cognition, insofar as one cannot exist without the other. As Luisi and Houshmand (2010, pp. 85-86) elaborate:

[The] starting point is the interaction between the autopoietic unit and the environment. The living unit is characterized by biological autonomy and at the same time is strictly dependent on the external medium for its survival. There appears to be a contradiction here, and life must indeed operate within this apparent contradiction. The interaction with this environment is always a very specific one, in the sense that the interaction a butterfly has with the environment is different from the interaction a worm or a human being has with the environment

In other words, the internal structure of the organism changes and adapts according to its environment. The structure of the living organism, together with its previous history of perturbations, determines the reactions that new perturbations will induce. Changes, mutations, and evolution are here seen as the result of maintaining the internal structure of an autopoietic organism.

The term 'cognition' applies only to living entities, and not to the inanimate world. From unicellular to multicellular organisms, from plants to insects, fish and mammals, each one has its own type of cognition corresponding to a different level of life's complexity. Cognition, as seen here, contrasts with the representational/cognitivist model. This is because it consists in a mutual interaction between the inner structure of the system and the environment, in the sense that the environment is 'created' during interaction itself as, for example, when a spider creates a web. It is in this sense that enaction is the process of mutual bringing into existence: the organism with its sensorium 'creates' its own world; the environment allowing the living organism to come into being.

According to this theory, the very notion of consciousness derives from the autopoietic organization of life: there is no organic human life without consciousness, and there is no consciousness that is not embodied in organic life. This perspective culminated in the neurophenomenological method (Varela, 1996), which is, according to Varela (1997, in Rudrauf et al., 2003): 
grounded on a pragmatic will to progressively and systematically reduce the distance between subjective and objective [...] a way of narrowing the gap between the mental and the physical

\subsection{The free energy principle}

There have been recent attempts to formalize the enactive theory with brain physiology. This is known as the Free Energy Principle (FEP). On some generous articulations of this view, free energy minimization occurs not only in biological systems but also takes place in nonliving systems, ranging from synchronization of clocks, to the primordial soup and social networks. Although there are some variants of this hypothesis, it generally holds that organisms act to maintain themselves in their expected biological and cognitive states, and that they can only do so by minimizing their free energy, provided that the long-term average of free energy is entropy (Kirchhoff and Froese, 2017).

A cognitivist view of the free energy principle, however, conceives of the relationship between life and mind under the predictive mind hypothesis. This is a model associating minds with computational processes requiring semantic (i.e. contentful) properties, or allowing the possibility of the mind to be potentially realized independently of life, were it to be given artificial support.

A non-cognitivist approach to the free energy principle (Friston, $2009,2013)$, by contrast, implies that mentality is ubiquitous. This is a strong continuity view on particular concepts of life (viz. autopoiesis and adaptivity) and mind (basic and non-semantic). On the non-cognitivist view:

All systems that maintain their variables within a limited range of values can be understood as having some form of mentality or proto-mentality given that the FEP casts any system that is able to maintain structural integrity in the face of a fluctuating environment as engaged in predicting its own future states. That is, retaining integrity rests upon processes the function of which is to maximize model evidence-i.e., these processes exhibit self-evidencing dynamics (Kirchhoff and Froese, 2017, p. 18).

The enactive theory endorses the non-cognitivist view. Subjective phenomena should not be mistakenly understood as a powerful generative brain model of semantic mental representations (cognitivist free energy principle), nor as an application of processing neural maps used to 'recover' the structure of the external world by conceptual reflection on the state of the external environment (as argued by Damásio). On the enactive view, human experience is conceived of as an internal structure of pre-reflective dynamic interaction. Varela adopts the Buddhist notion of a virtual self-or a selfless self-and reconceives it on biological level. Enactivism, as informed by Buddhism, thereby assumes a unique perspective.

\subsection{Buddhist practice and meditation}

The western idea of self is very different from the eastern because the universe does not play an important or relevant role. The self is seen as the enclosed capacity "to order my own thoughts and my own life, to use reason as an instrument to control and order my own life ... what's really important is not the particular content of our feelings or thinking but the power to control it reflexively (Varela, 1997, p. 18).

Over the past two thousand years Buddhists have developed sophisticated philosophical, phenomenological, and epistemological notions of egolessness (or selflessness), which form the core of Buddhist thought.
The Dalai Lama then asked, "In the modern West, when one thinks 'I' or 'I am,' does this necessarily imply that the 'I' so conceived must be posited as being independent or autonomous?" Charles's answer was very Buddhist in flavor. "If you ask people, they say no. But in the way they actually live it, the answer is yes, very powerfully, and much more so than our ancestors who thought of themselves more as part of a larger cosmos. (Varela, 1997, p. 20).

Buddhists refuted the existence of a permanent, unchanging self. In general, all four philosophical schools within Buddhism agree in denying the existence of a self that has a separate nature from the psychological constituents. According to His Holiness the Dalai Lama,

"There are four major schools of Buddhist philosophy, among which we consider the Prāsangika Madhyamaka school to be the most profound. One school of thought identifies the self essentially with consciousness, whereas the Prāsangika school regards the self as something imputed on the basis of the collection of the aggregates, or the mind and body. The Svātantrika Madhyamaka and all the lower Buddhist schools regard the statement that phenomena exist merely as imputations, not by their own nature, as an expression of nihilism" (Varela, 1997, p. 117).

The self is a flow of our experience: feelings of sadness and so forth arise in response to certain experiences,

"If in fact the self does not truly exist, then apprehending the self as not being truly existent is, of course, in accord with reality ... For a person who has investigated whether or not the self is truly existent, and through this investigation gains some actual experience of the lack of true existence of a self, when for this person a sense of self starts to arise more strongly it would not arise with the sense of apprehending the self as truly existent. Rather, the self would be apprehended without the qualification of being either truly existent or not truly existent. It could also happen for such a person that, although the self appears as if it were truly existent, one knows that it's not. In this situation, the self is apprehended as being like an illusion. It appears in one fashion but one knows it doesn't exist according to that mode of appearance. Hence it's like an illusion." (His Holiness the Dalai Lama, in Varela, 1997, pp. 117-118).

As a practice, Buddhism requires involvement in the same way that scientists are involved in their work, or as a writer's mind is involved in writing (see Brockman, 1996). To these contemplative practices, the self is neither a thing nor an entity, but a process.

According to Evan Thompson (2014), the sort of focused attention practices-as developed by some Buddhist traditions-can be construed as techniques for attending to features of experience that we ordinarily ignore or neglect. In other words, adept meditators can see and notice things that we rarely ever do. Thus, Buddhist contemplative practices can be understood as a kind of phenomenological training that can serve the scientific study of mind.

In Buddhism, mental training is often described as a systematic process of familiarizing oneself with the present character of mental events. This training cultivates a capacity for sustained, attentive awareness of the moment-to-moment flux of experience (Thompson, 2006). This seems to tell against a reflective account of the self, because concepts do not always do justice to the full range of qualities we experience. In the Western tradition, we tend to think that consciousness is something that is either present or 
absent: you have it when you are awake, and lose it when you are knocked out. In the East, however, it is essential to distinguish modes of consciousness within the range of, what we in the West call, unconsciousness. Dreaming, lucid dreaming, deep and dreamless sleep, and so-called 'pure awareness' are examples of such modes. Indian philosophy's (see Kak, 1997) major aim is precisely the development of a taxonomy of modes of human consciousness (Thompson, 2014).

Western science, however, has not yet furnished for itself an adequate phenomenology of conscious experience. As such, it is essential that we open the channels for constructive dialogue with the Eastern tradition and its practitioners, thereby enabling their insights to inform our own investigations, and vice versa.

\section{The empirical study}

Here, we focus on the qualitative study, in which we used a Buddhist meditative practice as our intervention protocol. Buddhist mediation was chosen (instead of other possible kinds) in virtue of the autopoietic paradigm. We hope we were able to show, in the theoretical background, why the autopoietic paradigm, inspired in the Buddhist conception of the mind, is stronger in providing nonreductive explanation of subjective experience. Because subjective experience cannot be reduced to brain pictures and/or yes/no answers, this paradigm takes into consideration the rich first-person experience, in the attempt to combine it with third-person, quantitative, measurements.

In this experiment, we had two different groups: one attending a regular class, and another practicing a demanding attentional task, a guided meditation. Both groups were subsequently asked to qualitatively evaluate their experience through a psychological assessment. This psychological assessment covered: 1) altered states; 2) happiness awareness; 3 ) open awareness to the present; and 4) private-public consciousness. This allowed us, first, to compare control groups to experimental groups, and, second, to probe the experience with regard to its psychological characteristics.

\section{Materials and methods}

\subsection{Materials}

The materials comprised an intervention with a meditative practice, and four qualitative tests using the following psychological scales:

- Abnorme Psychischer Zustaende States of Consciousness (APZ) (Dittrich, 1998) was used to assess the qualitative properties of what is usually called an 'altered state'. The items in the scale aim to evidence: modifications of thought; intense emotional response; bodily schema changes; perceptual changes; synaesthesia; and meaning alterations, which are typically evoked during meditative practices.

- Subjective Happiness Scale (Lyubomirsky and Lepper, 1999) was used to assess global subjective experience. Two items evaluated absolute and relative personal experience; two others items evaluated absolute and relative external experience. SHS measures the construct of subjective happiness and well-being. This scale aims to assess, therefore, the self- and non-self perception experiences of happiness.

- Mindful Attention Awareness Scale (MAAS) (Brown and Ryan, 2003) was used to assess open awareness to the present. MAAS taps a unique quality of consciousness related to, and predictive of, pre-reflective self-experience.

- Self-consciousness Scale - Revised version (SCS-R) (Scheier and Carver, 1985) was used to assess private-public self- consciousness, considered as sustained consciousness that is relatively stable over time.

The contents and constructs evaluated by each scale are summarized in Table 2. An example of the questions posed to the participants is given for each self-report measure. For instance, in the APZ scale, the main construct evaluated was self-boundaries alterations, composed of 23 binary items. An example of a variable assessed was: "Sounds and noises seemed different from what they usually are.". For the SHS scale, the main construct evaluated was that of self and non-self experiences of happiness, composed of six items on a [0; 7] scaling. An example of a variable assessed was: "Some people are generally very happy. They enjoy life regardless of what is going on, getting the most out of everything. To what extent does this characterization describe you?". Moreover, for the MAAS scale, the main construct evaluated was open-awareness experiences, composed of 15 items on a $[1 ; 6]$ scaling. An example of a variable assessed was: "I find it difficult to stay focused on what's happening in the present.". Finally, for the SCS-R scale, the main construct evaluated was private and public self-consciousness, composed of 23 items on five-point Likert scale. An example of a variable assessed was: "I often daydream about myself.".

\subsection{Intervention protocol: meditative practice}

It is well-established that a variety of mind-body techniques, including yoga, mental imagery, hypnosis, biofeedback, and meditation, are effective at addressing symptoms such as pain, anxiety, nausea, and insomnia. These techniques also help with a variety of medical, emotional, and behavioral issues (Culbert, 2017).

Meditative practice has been shown to play a physiological role in inducing neuroplastic changes in amygdala activity (Leung et al., 2017), as well as preventing age-related changes in cognitive functioning (Cotieret al., 2017). Meditative practice has been revealed as an effective alternative to pharmacology on blood pressure response (Park and Han, 2017), and as a successful cognitive behavioral therapy for epilepsy (Leeman-Markowski and Schachter, 2016). In addition, meditation intervention appears to promote a change in attentional focus from the internal to the present-moment external world, thereby having important implications for the treatment of anxiety (Xu et al., 2017), and generalized anxiety disorders (Hoge et al., 2017).

\subsubsection{Jhana meditation}

The Pali word Jhana (Sanskrit 'dhyana') is often translated as 'meditation', but more accurately refers to 'absorption' into a focused and stable state of concentration. In the classical tradition there are several stages of Jhana, each one more focused than the previous (Khema et al., 2001).

Traditional meditation is nowadays amenable to greater scientific understanding. For example, meditation has the short-term goal of stimulating the reward dopaminergic system. If the reward is greater than expected, dopaminergic neurons in the Ventral Tegmental Area (VTA) in the brain stem are activated. The VTA in turn innervates the nucleus accumbens (NAc) in the ventral striatum, which leads to higher centers in the orbital frontal cortex (OFC). Human studies have shown that activity in the medial OFC at the time of a reward correlates with subjective reports (Hagerty et al., 2013). According to Hagerty et al. (2013), Jhana meditation has also been associated with specific brain correlates, which may characterize the subjective experience of classical Jhana meditation: (1) external awareness diminishing; (2) internal verbalizations fading; (3) self-boundaries alteration; (4) increase of focused attention; and (5) well-being. The brain correlates, obtained by fMRI (BOLD signal) and qEEG (bands power), consisted in: (1) decreased activation compared to 
Table 1

Descriptive analysis.

\begin{tabular}{|c|c|c|c|c|c|c|c|c|c|c|}
\hline \multicolumn{2}{|c|}{ Descriptive Analysis } & \multirow{2}{*}{$\frac{\text { Instrument }}{\text { Variable }}$} & \multicolumn{2}{|c|}{ Biometric Data } & \multirow{2}{*}{$\begin{array}{l}\text { Abnormer Psychischer } \\
\text { Zustand Scale }\end{array}$} & \multirow{2}{*}{$\begin{array}{l}\text { Subjectiove } \\
\text { Happiness Scale }\end{array}$} & \multirow{2}{*}{$\begin{array}{l}\text { Mindful Attention } \\
\text { Awarness Scale }\end{array}$} & \multirow{2}{*}{$\begin{array}{l}\text { Self-Consciousness } \\
\text { Scale (Total) }\end{array}$} & \multirow{2}{*}{$\begin{array}{l}\text { Self-Consciousness } \\
\text { Scale (Private) }\end{array}$} & \multirow{2}{*}{$\begin{array}{l}\text { Self-Consciousness } \\
\text { Scale (Public) }\end{array}$} \\
\hline & $\mathrm{N}$ & & Age & BMI & & & & & & \\
\hline \multirow[t]{8}{*}{ Total } & 92 & Mean & 21,67 & 21,6627 & $21,79 \%$ & $79,43 \%$ & $66,45 \%$ & $69,33 \%$ & $71,38 \%$ & $77,69 \%$ \\
\hline & & Median & 21,36 & 21,0937 & $17,39 \%$ & $78,57 \%$ & $65,56 \%$ & $69,70 \%$ & $74,07 \%$ & $76,19 \%$ \\
\hline & & $\mathrm{SD}$ & 1538 & 2,68483 & $25,10 \%$ & $8,64 \%$ & $10,12 \%$ & $25,10 \%$ & $25,10 \%$ & $25,10 \%$ \\
\hline & & Minimum & 19 & 17,57 & $0,00 \%$ & $54,00 \%$ & $46,00 \%$ & $26,00 \%$ & $19,00 \%$ & $24,00 \%$ \\
\hline & & Maximum & 26 & 32,64 & $70,00 \%$ & $100,00 \%$ & $94,00 \%$ & $89,00 \%$ & $100,00 \%$ & $100,00 \%$ \\
\hline & & P25 & 20,46 & 19,8177 & $4,35 \%$ & $75,00 \%$ & $59,17 \%$ & $60,98 \%$ & $62,96 \%$ & $66,67 \%$ \\
\hline & & P50 & 21,36 & 21,0937 & $17,39 \%$ & $78,57 \%$ & $65,56 \%$ & $69,70 \%$ & $74,07 \%$ & $76,19 \%$ \\
\hline & & P75 & $22,53 \%$ & $23,0518 \%$ & $34,78 \%$ & $85,71 \%$ & $73,33 \%$ & $75,76 \%$ & $81,48 \%$ & $90,48 \%$ \\
\hline
\end{tabular}

Table 2

Self-report measurement.

\begin{tabular}{|c|c|c|c|c|}
\hline \multicolumn{5}{|c|}{ Subjective Experience Assesment } \\
\hline Scale & Constructs & N. Items & Scaling & Variables (items) example \\
\hline $\mathrm{APZ}$ & Self-boundaries alteration & 23 & binary & $\begin{array}{l}\text { "Sounds and noises seemed different from what they usually are." } \\
\text { "Time passed faster than usually." } \\
\text { "My body seemed bigger/longer than before." }\end{array}$ \\
\hline SHS & $\begin{array}{l}\text { Self and non-self experiences } \\
\text { of happiness }\end{array}$ & 4 & {$[0 ; 7]$} & $\begin{array}{l}\text { "Some people are generally very happy. They enjoy life regardless of what is going on, getting the } \\
\text { most out of } \\
\text { everything. To what extent does this characterization describe you?" } \\
\text { "Some people are generally not very happy. Although they are not depressed, they never seem as } \\
\text { happy as they } \\
\text { might be. To what extent does this characterization describe you?" }\end{array}$ \\
\hline MAAS & Open-awareness experiences & 15 & {$[1 ; 6]$} & $\begin{array}{l}\text { "I find it difficult to stay focused on what's happening in the present." } \\
\text { "I get so focused on the goal I want to achieve that I lose touch with what I'm doing right } \\
\text { now to get there." } \\
\text { "I tend not to notice feelings of physical tension or discomfort until they really grab my attention." }\end{array}$ \\
\hline SCS-R & $\begin{array}{l}\text { Private \& public } \\
\text { Self-consciousness }\end{array}$ & 23 & $\begin{array}{l}\text { five-point } \\
\text { Likert scale }\end{array}$ & $\begin{array}{l}\text { "I generally pay attention to my inner feelings." } \\
\text { "I often daydream about myself." } \\
\text { "I know the way my mind works when I work through a problem." }\end{array}$ \\
\hline
\end{tabular}

the rest state in the visual (BA 17-19) and auditory (BA 41-42) processing areas; (2) decreased activation compared to the rest state in Broca's area (BA 44,45) and in Wernicke's area (BA 39,40); (3) decreased activation compared to the rest state in the orientation area (BA5); (4) increased activation compared to the rest state in the Anterior Cingulate Cortex (ACC) (BA 32,33); and (5) increased activation compared to the rest state in the dopamine reward system of the brain (NAc in the ventral striatum and medial OFC). Reciprocal connections between the NAc and the medial OFC were found (D'ardenne et al., 2008). The authors suggest the possibility of activating a feedback loop between the two (Hagerty et al., 2013).

In this study, Jhana meditative practice was adopted in the experimental group to promote this possible feedback loop, by switching attentional focus to the conscious experience present in the different stages of this type of meditation.

\subsection{Study design}

This is a randomized, controlled, multicentered and single blinded study. The study, approved by the ethics committee of the Faculty of Medicine, University of Lisbon, was carried out in LIMMIT Lab at the same university as the centralizing research unit, and in collaboration with SalivaTec (Molecular Cognition(G)), Institute of Health Sciences (ICS), Center for Interdisciplinary Research in Health (CIIS), Universidade Católica Portuguesa, Viseu, Portugal, and the Mind-Brain Doctoral College, University of Lisbon.

The study consisted of two groups: a control group attending a regular class, and the intervention group practicing a guided meditation that aimed to promote conscious experience. After this practice, all the participants (control and intervention) were asked to qualitatively evaluate (posttest design) the experience in relation to: 1 ) altered states; 2 ) happiness awareness; 3 ) open awareness to the present; and 4) private-public self-consciousness. Participants were asked to conduct this qualitative evaluation using the four psychological scales outlined above.

\subsubsection{Sampling and population of the study}

For this study, students from the University of Lisbon (Faculty of Medicine, Faculty of Economy, Faculty of Sciences, and The School of Social and Political Sciences) were recruited. A convenience sample of 128 healthy volunteers, students at the University of Lisbon, non-meditators, were recruited and screened by the inclusion criteria, in order to achieve a proportion of 50\% men. Subjects received information and gave informed consent as they enrolled in the study.

3.3.1.1. Sample screening and group characterization. Screening was conducted through a general questionnaire, concerning the following (a) inclusion criteria: 1) 19-25-year-old young adults; male/female; 2) cultural background: university students; 3) normal body mass index (BMI), and 4) non-medicated excepting birth control pills; and (b) exclusion criteria: 1) serious physical illness or uncontrolled disorders of kidney liver, lung, heart, musculoskeletal, rheumatologic, metabolic, neurological or psychiatric; 2) severe chronic or terminal disease, which might affect the CNS or PNS; 3 ) pregnant or breastfeeding women; 4) abuse of alcohol or addictive substances, prior to the experience.

The allocation was randomized and parallel assigned, based on the students that were attending different lectures. Both experimental and control arm, with a 1:1 allocation, was conserved. The blinding was maintained in the interventions protocol and partially in the assessment protocol. 


\subsection{Statistical analysis}

We used the following software for (i) statistical and data management: IBM SPSS Statistics 22- significance level = 5\%; and (ii) laboratory information management: LabWare ${ }^{\mathrm{TM}}$ LIMS.

\subsubsection{Descriptive and exploratory analysis}

Frequency tables (simple/double entries) were used. Scale variables were summarized as mean, standard deviation, median, quartiles, minimum, maximum and/or others order statistics, when the sample distribution justified it. Categorical variables were summarized using frequency and percentage. When the scale of measure was ordinal, order statistics were considered, e.g. tercile. Boxplots were used as a graphic exploratory tool. Moreover, Spearman's rank correlation coefficient was applied.

\subsection{Sample size study}

The full sample size study is supported by the previous preliminary results of the experimental group [Martins et al., 2016], and, bearing in mind that the main objective was to test the research hypothesis that led to full study (i.e. the evidence that there is a significant change in the proteome profile in the subphenomes characterized in this paper), the following approach was designed. It was, for that purpose, considered a potency (T-Student) of $80 \%$, a significance level of $5 \%$, and an effect size corresponding to $40 \%$ of the estimated value for the standard deviation of the variation of the molecular weights in the preliminary study, executed before proposing this qualitative evaluation. Taking into account this option, that corresponds to a medium Cohen's effect size, an appropriate sample size for each group (experimental and control) of 64 elements was found.

\subsection{Results and discussion}

Through a guided meditation subjects were led to evoke a conscious experience, and later asked to evaluate the experience. We tested the qualitative relation between this experience and 1) altered states; 2 ) happiness awareness; 3 ) open awareness to the present; and 4) private-public self-consciousness.

The sample was separated into independent groups: (a) experimental group (64 subjects), and (b) control group (sham intervention) (64 subjects). Then, these groups were stratified by the subjective assessments protocol into Top and Bottom Phenomes, by a statistical strategy, which will further inform the interpretation of a pre-molecular clinical stratification. ${ }^{3}$ This first clinical subtyping permitted a stratification resulting in four groups: (i) the Top Experimental Phenome; (ii) the Top Control Phenome; (iii) the Bottom Experimental Phenome and (iv) the Bottom Control Phenome, as shown in Fig. 1.

The four subphenomes (groups) were tested for comparability statistics and external biometric data, possibly confounding variables, and were considered comparable for age, gender and BMI. The qualitative study allowed us not only to characterize the subjective experience of the whole sample (Table 1 ), but also to look at the differences between the performances of the experimental group in the meditative practice versus the control group attending a class.

As displayed in Fig. 2, there is a clear distinction between the experimental and control groups. The qualitative performance of the psychological task (four scales) allowed us to identify four groups: (1) top experimental group (the higher tercile) constituting

\footnotetext{
${ }^{3}$ Forthcoming by the authors and collaborators.
}

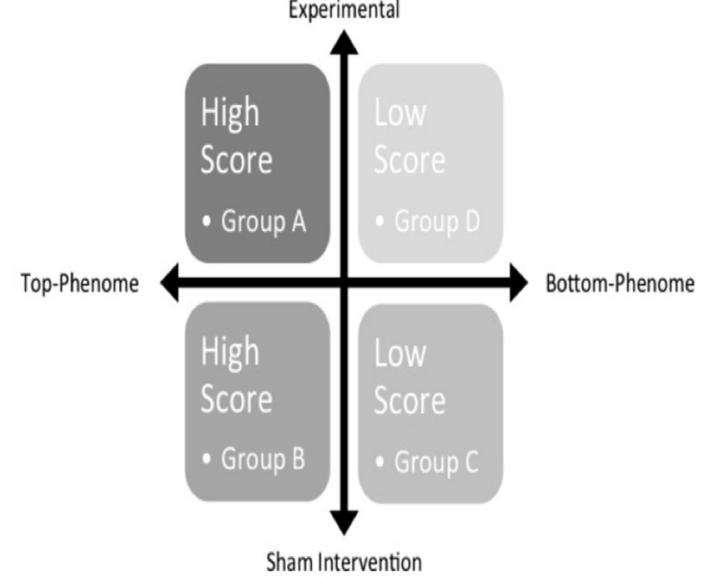

Fig. 1. Stratification of the four groups.

the sample of the best performances during the intervention; (2) the top control group (the higher tercile) indicating the best subjects to focus during the class; (3) the bottom experimental group (the lower tercile) constituting the group of subjects that performed lower (lack of focus) during the intervention; (4) the bottom control group (lower tercile) constituting the group that performed lower (lack of focus) during the class.

Figure 3 presents the comparative results of the phenomenological descriptions of each of the four subgroups. As illustrated in Fig. 2, the four subgroups performed differently on the overall scores of self-report measures. This suggests specific constructions of subjective experience, which resulted in the four subgroups: 1) top experimental group; (2) top control group; (3) bottom experimental group; and (4) bottom control group. These specific psychological characteristics can further be correlated to a specific molecular expression. In Fig. 3, as a proof of concept, we describe the same variables as in Table 2 . These variables, or questions posed to the participants in the qualitative assessment, are dissected discretely and ubiquitously for all items of the self-report measures. For instance, in the APZ scale the (1) top experimental group (0.60) reported that "Sounds and noises seemed different from what they usually are"; while (2), the top control group, and (3), the bottom experimental group, did not report this (0.91); while (4), the bottom control group, did not consider the question at all (0).

On the SHS scale, the (1) top experimental group appeared frequently against the statement: "Some people are generally very happy. They enjoy life regardless of what is going on, getting the most out of everything. To what extent does this characterization describe you?". This was less true of (2), the top control group; even less so of (3), the bottom experimental group; and only moderately true of (4), the bottom control group.

On the MAAS scale, (1), the top experimental group, somewhat infrequently "... found it difficult to stay focused on what's happening in the present", while for (2), the top control group, this was almost never reported; for (3), the bottom experimental group, somewhat frequently reported; and for (4), the bottom control group, this was infrequently reported.

On the SCS-R scale, (1), the top experimental group, report that "daydreaming about themselves" pertains greatly to them; while (2), the top control group, report that the statement pertains only a little to them; (3), the bottom experimental group, report that the statement somewhat pertains to them; and (4), the bottom control group, reported that the statement does not pertain to them at all.

The intervention with a guided meditation and the qualitative assessment with the four psychological scales, allowed us to: 


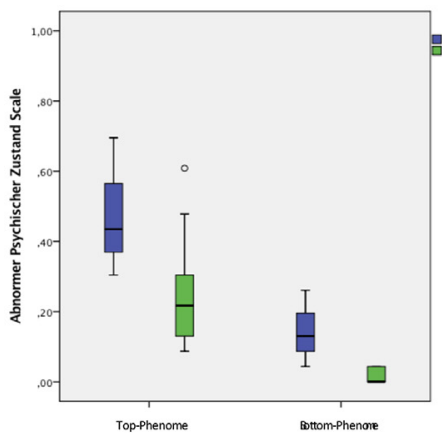

A)

Self Awareness Self Consciousness SubPhenome (N23) Reflective Self Pre-Reflective Self N92

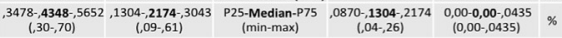

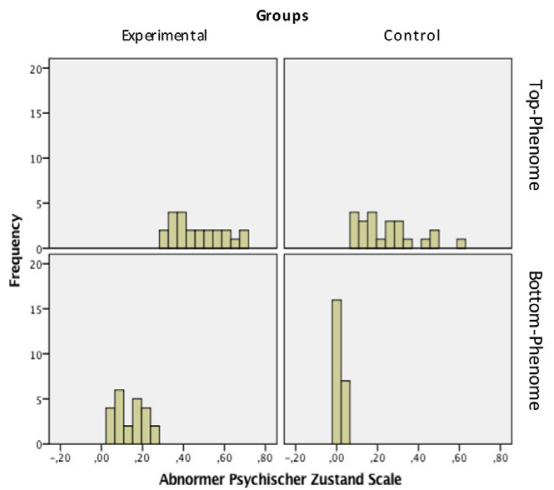

Abnormer Psychischer Zustand Scale. A) Boxplot; B) Histogram

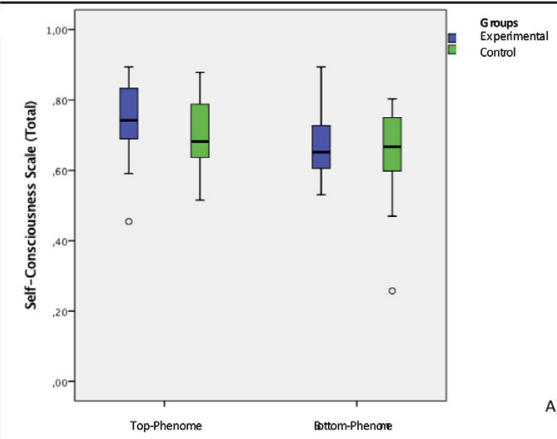

Self Awareness Self Consciousness SubPhenome (N23) Reflective Self Pre-Reflective Self N92

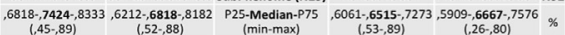

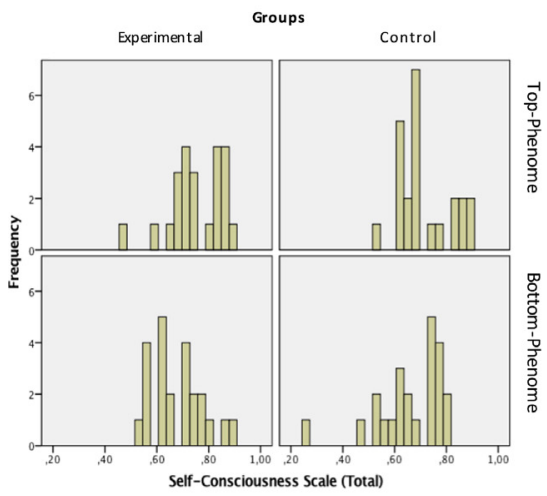

Self-Consciousness Scale Revised (Total). A) Boxplot; B) Histogram

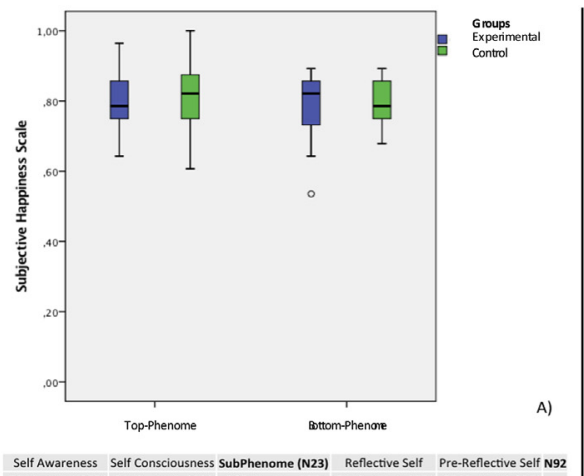

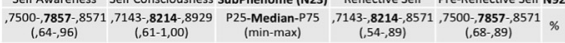

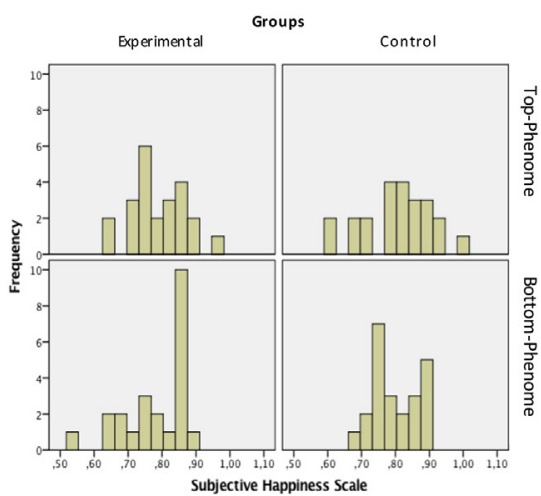

Subjective Happiness Scale. A) Boxplot; B) Histogram

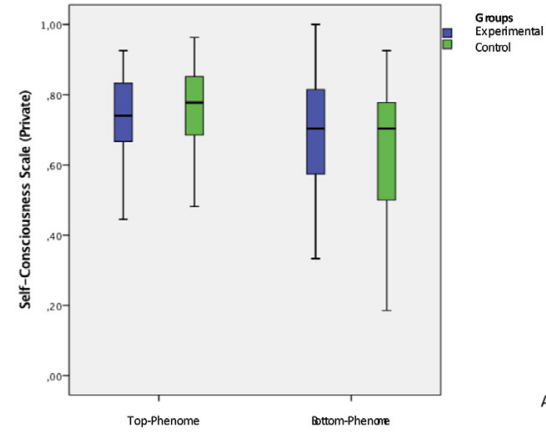

Self Awareness Self Consciousness SubPhenome ( $N 23$ ) Reflective Self Pre-Reflective Self N92

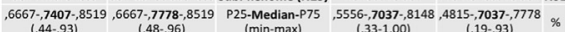

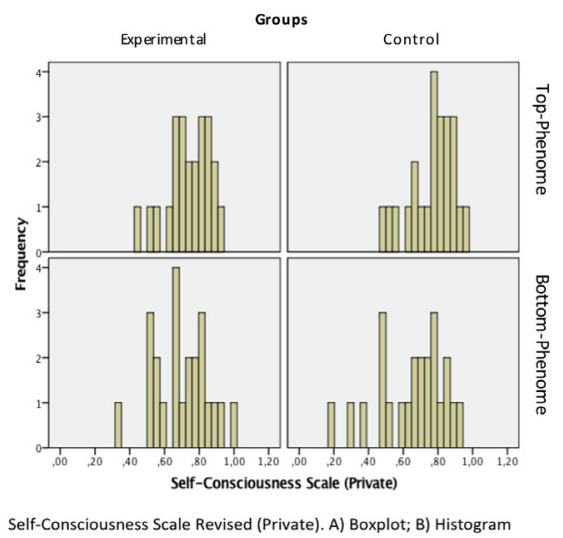

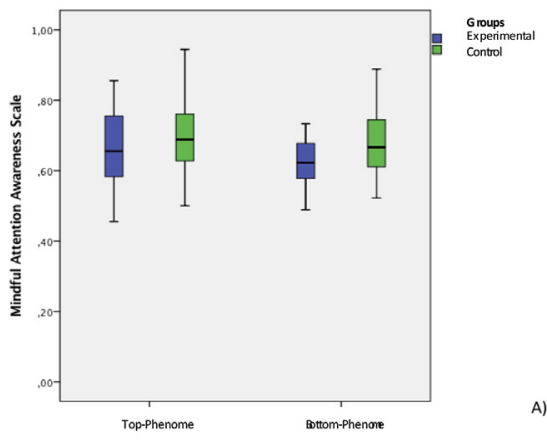

Self Awareness Self Consciousness SubPhenome (N23) Reflective Self Pre-Reflective Self N92

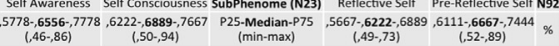

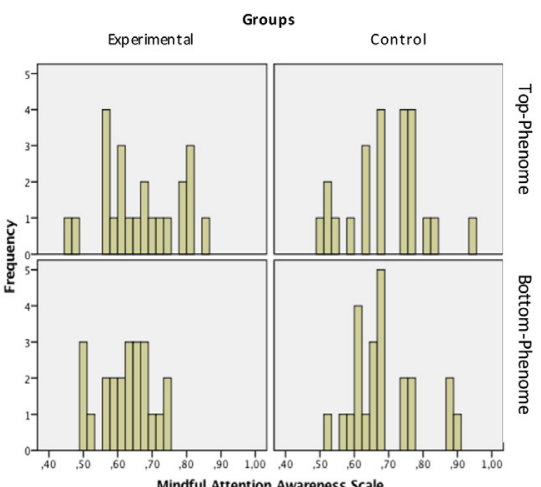

Mindful Attention Awareness Scale. A) Boxplot; B) Histogram

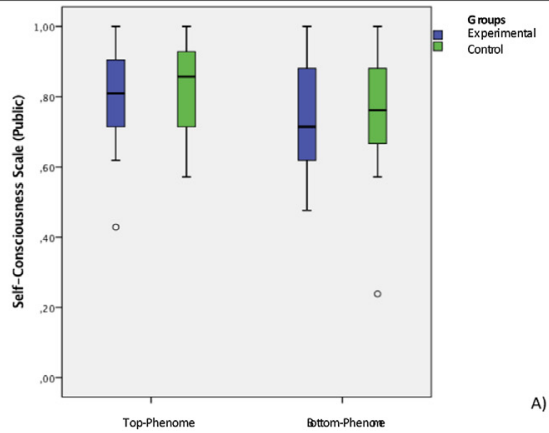

Self Awareness Self Consciousness SubPhenome (N23) Reflective Self Pre-Reflective Self N92 7143-, 8095-,9048, 7143-8571-,9524 P25-Median-P75, 6190-,7143-,9048, 6667-,7619-9048\%

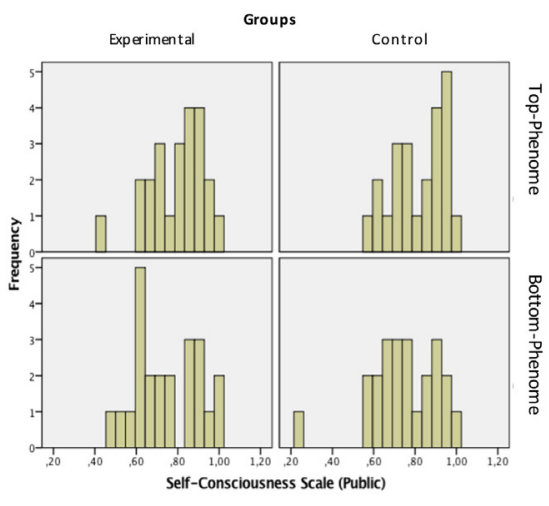

Fig. 2. Qualitative performance control vs. experimental groups. 

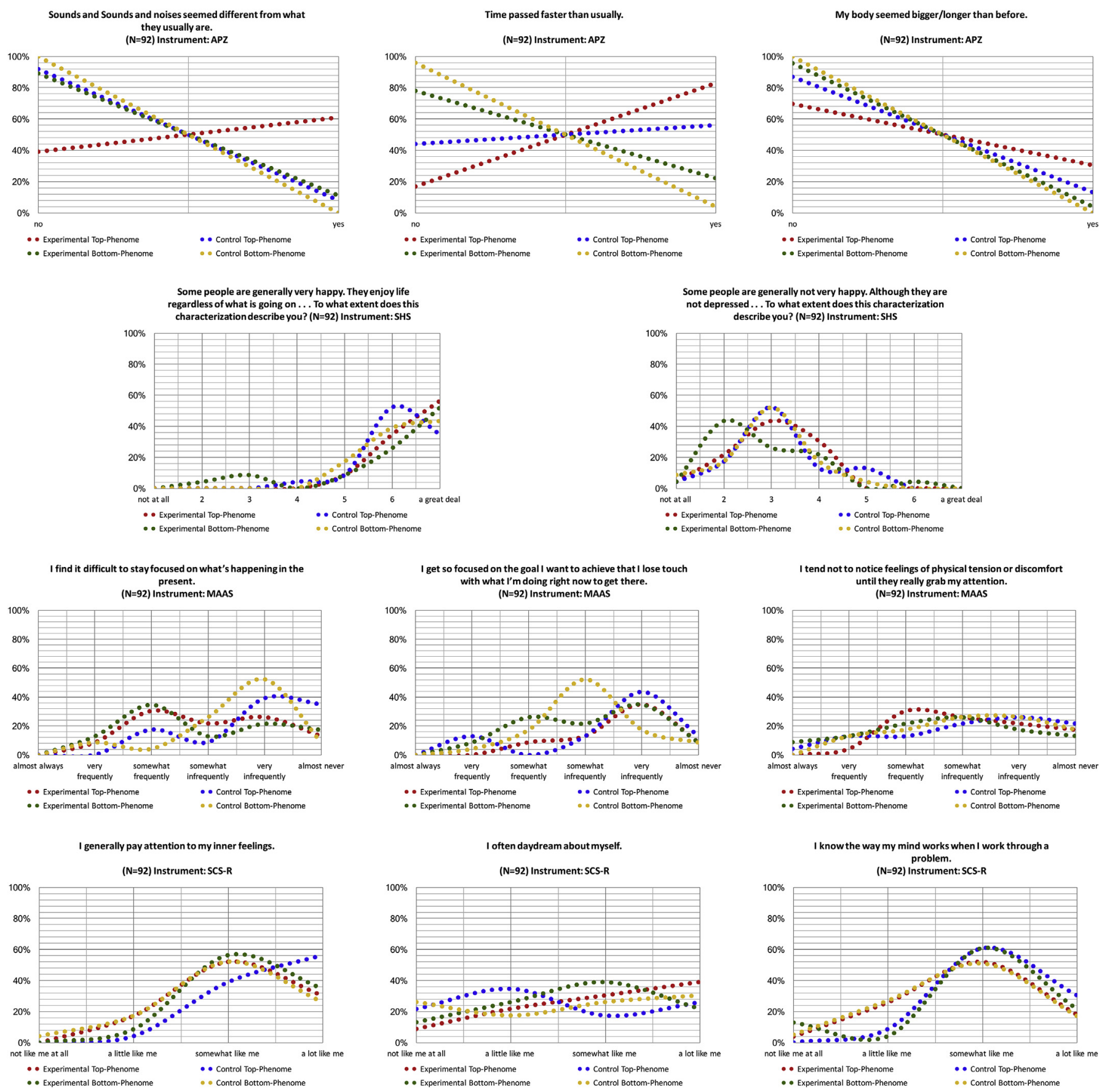

Fig. 3. Comparative results of the phenomenological reports.

(1) Identify experiential profiles based on the subjects' evaluations of their own conscious experience, and

(2) Clinically and phenomenologically understand the groups, and their subtypes, to motivate the investigation of protein correspondence (i.e., quantifying the differences in their proteomic profiles).

The model presented here bears resemblance to the neurophenomenological method, which proposes to introduce into brain research on subjectivity and consciousness first-personal methods of examining experience. Our method, however, constitutes a variation insofar as the quantitative part of the study does not consist in a brain-centered methodology. Another point of difference regards the qualitative evaluation: our participants are not trained in the phenomenological method, that is, they complete the intervention naively. Our quantitative method instead consists in a functional protein profile (proteomics), that is, dynamic protein information that is distributed along the organism itself.

The aim of this study is the understanding of molecular interactions induced by an intervention protocol. We focus on the whole: the proteome, referring to the entire set of proteins produced or modified by an organism or system. Commonly, there are two biochemical methodologies used to study a biological system: a) directed studies (classical biochemical studies), and b) enlarged studies (the omics biochemical studies). This work is not intended as a directed analysis into a specific or exact candidate neural 
pathway or phosphorylation process. The sensibility and specificity necessary to conduct such a study is virtually impossible. Rather, we propose a study with a different magnitude, i.e. an enlarged, non-directed perspective, or an omics study. We intend to probe physical interactions between molecules, as an example of "topdown" systems biology, taking an overhead-as well as overallview of a biosystem (Bruggeman and Westerhoff, 2007; Kiemer and Cesareni, 2007). The work is proposed as a systems biology paradigm, usually defined by contrast to a reductionist biological organization. As Denis (2006) notes, "Systems biology [...] is about putting together rather than taking apart". As a method, omics comprises high-throughput analytic techniques (Romualdi et al., 2009). These techniques include, for example, transcriptomics, metabolomics or proteomics, to propose specific testable hypotheses (Alberghina and Westerhoff, 2005); for instance, the result of an experimental induction. Normally, the output of an omics study is a multi-database generation (Baitaluk, 2009). Specifically, in future publications, it will be generated layered results of total proteins profiles, simultaneous immunedetections and quantifications and in-silico characterization, using bioinformatics tools, like cytoscape $^{\circledR}$ and panther ${ }^{\circledR}$. Top-down systems biology like these could in principle identify molecular interaction networks (Bruggeman et al., 2007). Although there are still today explanatory limitations, the interaction between molecular networks can be correlated to observed behavior of subjective experience, evaluated through self-report measures. Explanatory limitations include, for instance, the incapability of connecting a specific neural pathway to a specific self-reported behavior. Indeed, such an explanatory error resides in the inability to rule out preliminary reasoning, suggesting that such behavioral-molecular correlations were present in the first place.

Subjective experience has been studied as the macroscopic cartography of synaptic connections in a macro-network, but could also be probed on an intra-cellular scale: a micro-network. Those neural networks are regulated upwards or downwards via intracellular regulatory networks of the transcriptome interfaces (Foster, 2015). Insufficient findings describe specific molecular networks that can be elicited through inducting a specific subjective experience. This scientific gap motivates setting up an omics approach. The object of this study is the interplay between mind, body, environment and behavioral characteristics. In specific, this study concerns how subjective experience modulates objective biological measurements (Ulvestad, 2012). Omics methodologies have been recently gathering a complex and extensive quantity of data enabling biomedical sciences to assimilate and define a systems biology framework. Methodologies such as the one proposed by Ritchie and colleagues (2015), assesses biological systems via multi-omics, i.e., from transcriptome to phenome. Omics studies began to characterize different biological substrates. Nevertheless, such studies have only recently looked into neuronal structures (English et al., 2012), giving access to solid neuroproteomics databases (Collins et al., 2006; Behan et al., 2009; Hahn et al., 2009; Ishii et al., 2009; Bayés et al., 2011). We propose that omics studies advance towards insights into the biomolecular underpinnings of subjective experience, for instance, the physiological mechanisms involved in strong emotional states (Chiappelli et al., 2006). Such an advancement in omics studies would offer a neuroscientific approach to the hard problem of consciousness (Susan et al., 2005). Nevertheless, no publication yet has used analytical proteomic techniques to evaluate physiological states resulting from the expression of self-conscious experience (Martins et al., 2016). Indeed, the difficulty surrounding such research consists in the fact that self-conscious experience varies both with time, and with the amount of environmental stress that an organism undergoes.

\section{Conclusion}

It is a standard of modern Western scientific physiology to study natural life by quantifying and measuring the correlation between behavior and brain function. On our model, however, we focused on the qualitative experience of a meditative state, centering our method within a fruitful and mutually informative dialogue between Western objective (reproducible) experiments, and Eastern subjective analysis. What makes our research innovative is its starting-point in qualitative assessment, which subsequently directs the interpretation of quantitative measurements of proteomics.

We found substantial differences between the control and the experimental group, allowing us to conclude that the experimental group was able to identify, describe, and report a subjective experience intrinsic to Jhana meditation. The intervention with Jhana meditation and the qualitative assessment, implementing the four psychological scales, allowed us to: (1) distinguish experiential profiles based on the subjects' evaluations of their own conscious experience; and (2) define a clinical subtyping strategy. We identified, in the experimental group, two sub-groups: the higher and the lower tercile. In the control group, we also found two subgroups: the higher and the lower tercile. These four tercile groups will be further compared with the protein variations.

The study focused on the first-person experience associated with cognitive and mental events. Cognitive processes appear relevant and manifested for the subject that can provide an account. We explored the first-person account because the familiarity we have with subjective life must give way in favour of the careful examination of what it is that we can and cannot have access to, and how this distinction is not rigid but variable. This first-person methodology appears as crucial because without a sustained examination we actually do not produce phenomenal descriptions that are rich and subtly interconnected enough in comparison with third-person accounts, that is, quantitative measurements (Shear and Varela, 1999). To our knowledge, Jhana meditation has not yet been studied on a first-person account. We aim in the future to complement this study with synamic protein information (proteomics). This physiological approach, measured by changes in functional protein networks, might prove to be a promising framework for objective, enactive research design. "Enaction", as conceived by Thompson and Stapleton (2009), grounds subjective experience in macro-micro network interactions. A follow-up study, to include molecular descriptions, will supplement the psychological analysis of subjective phenomena as presented here. Namely, the acquisition of multi-omics data of the subjective experience of jhana meditation. The first-person account characterizes and stratifies the sample into 4 distinct groups, by multiple comparisons of the psychological scales variables, with a good internal consistency and reliability. Afterwards, the expected total protein profile ( $\mathrm{t} 0$ ) of the 4 groups/subphenomes, characterized by capillary electrophoresis, should be discrete. Then, the total protein profile difference ( $\mathrm{t} 1-\mathrm{t} 0$ ) of the 4 groups/subphenomes should show a constant variability in specific proteomic bands, e.g. inflammatory molecular weight range [17 kDa-33 kDa], characterized by capillary electrophoresis. Henceforward, in silico analysis, cytoscapeTM and pantherTM, will generate functional protein networks, of the different 4 groups of the precise biological processes, e.g. inflammation, of the neuronal-oral database created with Uniprot $^{\mathbb{R}}$ referencing. After accomplishing this tasks, a simultaneous immunedetection multiplexed analysis of the Th17 cytokine and neuropeptides, e.g. substance-p, oxytocin, panel separates and quantifies the neuroinflammatory and neuropeptide molecular response of the 4 distinct groups, and the individual neurophysiological response. Finnaly, a graphical user interface toolbox will 
provide exploration, visualization and integration of the different datasets, with several datamining algorithms e.g. expectationmaximization and principal component analysis.

In our study, we adopted a methodology that can provide an open link to objective, empirically based description. The overall results of the qualitative, first-person, study should move towards an integrated or global perspective on mind where neither experience nor external mechanisms have the final word (Shear and Varela, 1999). The mind-life perspective requires a reciprocal influence and determination of first- and third-person accounts. In this paper, we studied phenomenal data as a crucial fact for the domain of living beings, which, we expect, can provide the ground for a subsequent third-person study.

\section{Acknowledgements}

We would like to acknowledge the special contributions of Teresa Rodrigues from IMM, Faculty of Medicine, University of Lisbon, Portugal; Nuno Rosa, Maria Jose Correia, and Marlene Barros from the Institute of Health Sciences (ICS), Center for Interdisciplinary Research in Health (CIIS), Universidade Católica Portuguesa, (Viseu, Portugal); and Mário Simões from LIMMIT lab, Faculty of Medicine, and Mind-Brain College, from the University of Lisbon, Lisbon, Portugal. The authors also wish to thank Michael Kirchhoff for his insightful comments on the paper, and the Lisbon Wide Minds Group for the fruitful discussion during the presentation of the project at Nova University of Lisbon. The authors would like also to thank the important comments of the reviewers, and the patience of the editors. Inês Hipolito would like to acknowledge that this paper was made possible by an International Postgraduate Award from the University of Wollongong, Australia.

\section{References}

Alberghina, L., Westerhoff, H.V., 2005. Systems Biology: Definitions and Perspectives (Topics in Current Genetics).

Baitaluk, M., 2009. System biology of gene regulation. Biomed. Informat. 569, 55-87.

Bayés, À., van de Lagemaat, L.N., Collins, M.O., Croning, M.D., Whittle, I.R. Choudhary, J.S., Grant, S.G., 2011. Characterization of the proteome, diseases and evolution of the human postsynaptic density. Nat. Neurosci. 14 (1), 19-21.

Behan, A.T., Byrne, C., Dunn, M.J., Cagney, G., Cotter, D.R., 2009. Proteomic analysis of membrane microdomain-associated proteins in the dorsolateral prefrontal cortex in schizophrenia and bipolar disorder reveals alterations in LAMP, STXBP1 and BASP1 protein expression. Mol. psychiatry 14 (6), 601.

Brockman, J., 1996. Third Culture: beyond the Scientific Revolution. Simon and Schuster.

Brown, K.W., Ryan, R.M., 2003. The benefits of being present: mindfulness and its role in psychological well-being. J. Pers. Soc. Psychol. 84 (4), 822.

Bruggeman, F.J., Westerhoff, H.V., 2007. The nature of systems biology. Trends Microbiol. 15 (1), 45-50.

Bruggeman, F.J., Hornberg, J.J., Boogerd, F.C., Westerhoff, H.V., 2007. Introduction to systems biology. Plant Syst. Biol. 1-19 (Birkhäuser Basel).

Chalmers, D.J., 1995. Facing up to the problem of consciousness. J. Conscious. Stud. 2 (3), 200-219.

Chiappelli, F., Iribarren, F.J., Prolo, P., 2006. Salivary biomarkers in psychobiological medicine. Bioinformation 1 (8), 331-334.

Collins, M.O., Husi, H., Yu, L., Brandon, J.M., Anderson, C.N., Blackstock, W.P., et al, 2006. Molecular characterization and comparison of the components and multiprotein complexes in the postsynaptic proteome. J. Neurochem. 97 (s1), $16-23$.

Cotier, F.A., Zhang, R., Lee, T.M., 2017. A longitudinal study of the effect of short-term meditation training on functional network organization of the aging brain. Sci. Rep. 7.

Crick, F., Clark, J., 1994. The astonishing hypothesis. J. Conscious. Stud. 1 (1), 10-16.

Culbert, T., 2017. Perspectives on technology-assisted relaxation approaches to support mind-body skills practice in children and teens: clinical experience and commentary. Children 4 (4), 20.

D'ardenne, K., McClure, S.M., Nystrom, L.E., Cohen, J.D., 2008. BOLD responses reflecting dopaminergic signals in the human ventral tegmental area. Science 319 (5867), 1264-1267.

Damásio, A., 1994. Descartes' Error: Emotion, Rationality and the Human Brain. Avon Books, New York.

Damásio, A., 2010. Self Comes to Mind: Constructing the Conscious Brain. Vintage.
Damásio, A.R., 1998. Investigating the biology of consciousness. Phil. Trans. R. Soc. Lond. B Biol. Sci. 353 (1377), 1879-1882.

Denis, N., 2006. The Music of Life: Biology beyond the Genome. Oxford University Press, Oxford.

Dittrich, A., 1988. Angst in außergewöhnlichen Bewusstseinszustände (Fear in ASC). In: Braun, H.J., Schwarz, A. (Eds.), Angst, Fear, Band 13. Zürcher Hochschulforum, Zurich. Verlag der Fachvereine Zurich.

English, J.A., Manadas, B., Scaife, C., Cotter, D.R., Dunn, M.J., 2012. Partitioning the proteome: phase separation for targeted analysis of membrane proteins in human post-mortem brain. PloS one 7 (6), e39509.

Foster, P.P., 2015. Role of physical and mental training in brain network configuration. Front. aging Neurosci. 7.

Friston, K., 2009. The free-energy principle: a rough guide to the brain? Trends cognitive Sci. 13 (7), 293-301.

Friston, K., 2013. Active inference and free energy. Behav. Brain Sci. 36 (03), $212-213$.

Godfrey-Smith, P., 1998. Complexity and the Function of Mind in Nature. Cambridge University Press.

Hagerty, M.R., Isaacs, J., Brasington, L., Shupe, L., Fetz, E.E., Cramer, S.C., 2013. Case study of ecstatic meditation: fMRI and EEG evidence of self-stimulating a reward system. Neural plast.

Hahn, C.G., Banerjee, A., MacDonald, M.L., Cho, D.S., Kamins, J., Nie, Z., et al., 2009. The post-synaptic density of human postmortem brain tissues: an experimental study paradigm for neuropsychiatric illnesses. PloS one 4 (4), e525.

Hayward, J., Varela, F., 1992. Gentle bridges: dialogues between the cognitive sciences and the Buddhist tradition. Mass. Shambhala Publ.

Hipólito, I., 2015. Proof phenomenon as a function of the phenomenology of proving. Prog. biophysics Mol. Biol. 119 (3), 360-367.

Hoge, E.A., Guidos, B.M., Mete, M., Bui, E., Pollack, M.H., Simon, N.M., Dutton, M.A., 2017. Effects of mindfulness meditation on occupational functioning and health care utilization in individuals with anxiety. J. Psychosomatic Res. 95, 7-11.

Ishii, A., Dutta, R., Wark, G.M., Hwang, S.I., Han, D.K., Trapp, B.D., et al., 2009. Human myelin proteome and comparative analysis with mouse myelin. Proc. Natl. Acad. Sci. 106 (34), 14605-14610.

Jackendoff, R., 1987. Consciousness and the Computational Mind. The MIT Press.

Jackson, F., 1982. Epiphenomenal qualia. Phil. Q. 32 (127), 127-136.

Kak, S.C., 1997. On the science of consciousness in ancient India. Indian J. Hist. Sci. 32, 105-120.

Khema, A., Brasington, L., Heinegg, P., 2001. Visible Here and Now: The Buddha's Teachings on the Rewards of Spiritual Practice. Shambhala Publications, p. 214.

Kiemer, L., Cesareni, G., 2007. Comparative interactomics: comparing apples and pears? Trends Biotechnol. 25 (10), 448-454.

Kirchhoff, M.D., Froese, T., 2017. Where there is life there is mind: in support of a strong life-mind continuity thesis. Entropy 19 (4), 169.

Koch, C., 2004. The quest for consciousness. Eng. Sci. 67 (2), 28-34.

Koffka, W., 1935. Principles of Gestalt Psychology. Routledge \& Kegan Paul Ltd, London.

Leeman-Markowski, B.A., Schachter, S.C., 2016. Treatment of cognitive deficits in epilepsy. Neurol. Clin. 34 (1), 183-204.

Leung, M.K., Lau, W.K., Chan, C.C., Wong, S.S., Fung, A.L., Lee, T.M., 2017. Meditationinduced neuroplastic changes in amygdala activity during negative affective processing. Soc. Neurosci. 1-12.

Luisi, P.L., Houshmand, Z., 2010. Mind and Life: Discussions with the Dalai Lama on the Nature of Reality. Columbia University Press.

Lyubomirsky, S., Lepper, H.S., 1999. A measure of subjective happiness: preliminary reliability and construct validation. Soc. Indicat. Res. 46 (2), 137-155.

Martinez-Conde, S., 2004. A review of christ of Koch's the quest for consciousness. PSYCHE 10 (1), 2.

Martins, J.E., Simõ̃es, M., Rosa, N., D'Alimonte, D., Mendes, V.M., Correia, M.J., Barros, M., Manadas, B., 2016. Happiness as a self state and trait of consciousness: clinical hypnosis and saliva molecular biomarkers - a brief revision. Exp. Pathology Health Sci. Res. Clin. Teach. Soc. 8 (1), 51-54.

Nagel, T., 1974. What is it like to be a bat? Phil. Rev. 83 (4), 435-450.

Park, S.H., Han, K.S., 2017. Blood pressure response to meditation and yoga: a systematic review and meta-analysis. J. Altern. Complementary Med.

Ritchie, M.D., Holzinger, E.R., Li, R., Pendergrass, S.A., Kim, D., 2015. Methods of integrating data to uncover genotype-phenotype interactions. Nat. Rev. Genet. $16(2), 85$.

Romualdi, C., Lanfranchi, G., 2009. Statistical tools for gene expression analysis and systems biology and related web resources. In: Bioinformatics for Systems Biology. Humana Press, pp. 181-205.

Rudrauf, D., Lutz, A., Cosmelli, D., Lachaux, J.P., Le Van Quyen, M., 2003. From autopoiesis to neurophenomenology: Francisco Varela's exploration of the biophysics of being. Biol. Res. 36 (1), 27-65.

Scheier, M.F., Carver, C.S., 1985. The self-consciousness scale: a revised version for use with general populations. J. Appl. Soc. Psychol. 15 (8), 687-699.

Shear, J., Varela, F.J., 1999. The View from within: First-person Approaches to the Study of Consciousness. Imprint Academic.

Simeonov, P.L., 2010. Integral biomathics: a post-Newtonian view into the logos of bios. Prog. biophysics Mol. Biol. 102 (2), 85-121.

Susan, A., Greenfield, Collins, T., 2005. A neuroscientific approach to consciousness. In: Laureys, S. (Ed.), Progress in Brain Research. Elsevier, p. 150.

Thompson, E., 2006. Neurophenomenology and contemplative experience. Oxf. Handb. Sci. Relig. 226-235.

Thompson, E., 2014. Waking, Dreaming, Being: Self and Consciousness in 
Neuroscience, Meditation, and Philosophy. Columbia University Press.

Thompson, E., Stapleton, M., 2009. Making sense of sense-making: reflections on enactive and extended mind theories. Topoi 28 (1), 23-30.

Ulvestad, E., 2012. Psychoneuroimmunology: the experiential dimension. Psychoneuroimmunology Methods Protoc. 21-23.

Varela, F.J., 1996. Neurophenomenology: a methodological remedy for the hard problem. J. Conscious. Stud. 3 (4), 330-349.

Varela, F.J., 1997. Sleeping, Dreaming, and Dying: an Exploration of Consciousness with the Dalai Lama. Mind and Life Institute.
Varela, F.J., 1999. The specious present: a neurophenomenology of time consciousness. Nat. phenomenology Issues Contemp. phenomenology cognitive Sci. $64,266-329$.

Varela, F.J., Thompson, E., Rosch, E., 1993. L'inscription corporelle de l'esprit: sciences cognitives et expérience humaine. Editions du Seuil.

Xu, M., Purdon, C., Seli, P., Smilek, D., 2017. Mindfulness and mind wandering: the protective effects of brief meditation in anxious individuals. Conscious. Cognition 51, 157-165. 